\title{
Proposal for a Four-Phase Stress Model
}

\author{
Marilda Novaes Lipp $₫$, Louis Mario Novaes Lipp \\ Institute of Psychology and Stress Control, São Paulo, Brazil \\ Email:mlipp@estresse.com.br, Louis.lipp@gmail.com
}

How to cite this paper: Lipp, M. N., \& Lipp, L. M. N. (2019). Proposal for a FourPhase Stress Model. Psychology, 10, 14351443.

https://doi.org/10.4236/psych.2019.1011094

Received: April 26, 2019

Accepted: August 19, 2019

Published: August 22, 2019

Copyright $\odot 2019$ by author(s) and Scientific Research Publishing Inc. This work is licensed under the Creative Commons Attribution International License (CC BY 4.0).

http://creativecommons.org/licenses/by/4.0/

\section{(c) (i) Open Access}

\begin{abstract}
Stress has been identified as a major risk factor for mental illness and its prevalence is rising globally, not only harming the workforce but also translating into an enormous cost to the labor organizations. To prevent and treat stress-related consequences, it is necessary to learn how to identify its symptoms and their severity. The present paper constitutes a proposal for a four-stage model of the stress process, adding a phase to Selye's three-phase model. The model identifies an intermediary phase between the resistance and exhaustion stages of the Selye model, possessing characteristics distinct from the other stages. This newly identified stage has been named the Nearexhaustion phase. Stress symptoms from a sample of 37,454 adult subjects were grouped according to the four proposed phases, which may be used as an aid for the diagnosis of stress. It is suggested that a four-phase stress process should replace Selye's three-phase model.
\end{abstract}

\section{Keywords}

Stress, Three-Phase Stage Model, Stress Four-Phase Model

\section{Introduction}

The World Health Organization has labeled stress as the "health epidemic of the $21^{\text {st }}$ century" (WHO, 2011). Indeed, according to the survey published in the WHO report, between 1983 and 2009 prevalence of stress in the United States rose from 10\% to 30\% (Fink, 2016). In Brazil, according to data published in the Social Security Statistical Bulletin (Previdência Social, 2011), depending on the occupation practiced, prevalence of stress jumped from 3\% to 19\% between 1996 and 2016, and the index of sick leave, caused by stress-related diseases in Brazilian workers, rose $28 \%$ in the first half of 2011, versus the same period in 2010 . Moreover, according to this bulletin, 100,000 people were absent from work as a result of this diagnosis, compared to 85,000 in the first half of the previous year, it being estimated that, in total, more than $\mathrm{R} \$ 30$ billion (circa US $\$ 7.5$ billion) is 
lost every year in Brazil as a result of occupational accidents and illnesses, with 3 to 4 out of every 10 Brazilians reporting significant stress symptoms. The literature indicates that exposure to stressful events throughout life has a negative impact on the physical and mental health of human beings (Fink, 2016). And research in the areas of neuroscience and psychoimmunology shows that the cumulative effect of stressors may lead to physical and psychological impairment (Wethington, 2016).

The diagnosis of stress cannot be arbitrary, as it requires an adequate understanding of what constitutes a stress reaction and of the symptomatological condition that characterizes it. The differential diagnosis of stress is only possible within the context of a theoretical reference and familiarity with the physical and psychological manifestations that go with it. A variety of methods have been proposed to evaluate stress, for example, through the significant stressors that have occurred in life, over a given period of time, or applying electrodermal measures, electromyography procedures, and cardiovascular indices among others. Scales that measure the occurrence of major stressors in people's lives, such as the Social Readjustment Rating Scale of Holmes \& Rahe (1967), is one of the methods frequently used to evaluate stress. The transactional theory of Lazarus \& Folkman (1984) emphasizes that it is the lesser threats, events of relatively minor importance, which, when added together, may generate stress, depending on how the individual perceives and interprets them. As people are different in terms of their levels of resilience and the way they interpret challenges, and as each individual has their own coping strategy, it becomes imprecise to evaluate stress purely on the basis of events occurring in one's life.

As far as physiological measurement is concerned, Everly \& Lating (2013) and Zangróniz et al., 2017, suggest it is possible to measure stress at the physiological level using electrodermal techniques, while Luijcks et al., 2014 made use of electromyography, and Sherwood et al., 2017 used cardiovascular measures. Selye (1984) himself, as well as McClelland, Ross, \& Patel (1985), stated that stress can be evaluated at a neuroendocrine level by way of a catecholamine index derived from samples of plasma, urine and saliva. Unfortunately, this type of evaluation is not generally available to all psychotherapists. One possible alternative is to diagnose stress by checking for symptoms that are already apparent (Zuckerman, 1960; Lipp, 2000). For this, it is essential to draw on a set of theoretical references that make it possible to categorize the ostensibly stress-related symptoms.

According to Hans Selye, the Hungarian-Canadian endocrinologist, and a pioneer in scientific studies in the area, stress is a non-specific response of the body when faced with any demand (Selye, 1975). The Fifth Edition of the Diagnostic and Statistical Manual of Mental Disorders (DSM-V) (APA, 2013) contains classifications of stress, such as acute stress, post-traumatic stress and adaptation disorders. Emotional stress not associated with traumatic events was assigned the designation of adaptation disorder and was defined by the DSM-V 
as "the presence of emotional or behavioral symptoms in response to an identifiable stressor" (APA, 2013: p. 287). Lipp (2017: p. 302) expanded on the notion of what constitutes stress with the following definition: "Stress is a state of functional disequilibrium that develops when faced with challenging situations leading to the organism using its psychobiological resources to cope with events that demand mobilizing action". It is an attempt to overcome a challenge, to survive a threat, whether real or imaginary. Essentially, it has at its root the need for the organism to cope with something that threatens its homeostasis or internal equilibrium.

\section{Discussion: The Evolution of the Stress Concept}

When Selye (1936) published his first article on stress in 1936, in the scientific journal Nature, the fabled "syndrome produced by diverse nocuous agents", his perception was that there was a syndrome that would likely represent "the corporeal expression of a total mobilization of the defense mechanisms" (Selye, 1965: p. 35). Selye suggested the designation "alarm reaction" for the initial response characterized by tissue catabolism, hypoglycemia, gastrointestinal erosion, discharge of secretory granules from the adrenal cortex, hemoconcentration, among others.

\subsection{The Three-Phase Model of Stress}

Subsequently, the same author (1950) noticed that, after the alarm reaction, if the nocuous agent continued to remain present and the organism was still alive, an adaptation or Resistance stage took place in which these symptoms disappeared or were reversed. This was designated the Resistance stage, a necessary step for survival which exhibited manifestations that were diametrically opposed to the alarm phase. Selye also noticed that, if the organism were exposed to these nocuous agents for an even longer period of time, the adaptation of the Resistance phase ended, with a third phase taking its place, namely Exhaustion. Selye gave the name "General Adaptation Syndrome" (GAS) to the process comprising the three phases, describing it as an integrated syndrome of closely interrelated adaptive reactions to non-specific stress itself.

The contribution of Selye's research studies is undeniably important to the area of health, and specifically stress, given the vast number of articles and books dealing with this topic published every year all over the world. However, some of the concepts he expounded have become the object of fresh perspectives (McCarty, 2016). For example, the notion of a nonspecific response has been disputed by authors who propose the existence of a distinction in the organism's response to different stressors (Pacak et al., 1998; Pacak \& Palkovits, 2001). This distinction has given rise to the notion of stressor specificity and a specific neuroendocrine response. As far as the definition of stress is concerned, Fink (2016) introduces other considerations involving the perception of a threat, resulting in anxiety, discomfort, emotional strain and difficulty in adapting. The author also 
states that stress occurs when the demands exceed one's self-perception of the ability to cope with them.

\subsection{A New Stage in the Stress Process}

Research conducted in the stress laboratory at the Catholic University of Campinas (PUCC), in Brazil, has led to a questioning of Selye's three-phase model (alarm, resistance and exhaustion). In 30 years of research and clinical work, Lipp (2000) realized that the resistance phase proposed by Selye was, in reality, very long, and that there was a possibility of it being broken down into two smaller phases. Many patients entering the Resistance phase went through a period in which, although not fully able to resist the pressures of life, were still not completely devoid of energy, being able to work and recuperate. The Resistance stage did not suddenly give way to the Exhaustion stage; in fact, there seemed to be an intervening period between Resistance and Exhaustion. Thus, the possibility of there being an intermediate phase between the stages of Resistance and Exhaustion was suggested. This hypothesis gained traction when statistical analyses of data collected from 1843 adults demonstrated the existence of four groups of symptoms that defined the seriousness of the stress process. Factor analyses were performed, which showed the organization of the symptoms identified in the sample among the factors. When factor extraction using the method of multiple correspondence analysis was reported, two important factorial axes were found: psychological symptoms on the one hand and physical symptoms on the other. Then, when factor analysis using the method of principal component analysis (PCA) was performed (with varimax rotation), four factors were found that, together, explained the variance. These four factors demonstrated four phases of stress. Lastly, confirmatory factor analysis (CFA) was performed, which showed four well-defined factors and one generic, secondary factor, that shares a variance with all the items, in other words, it measures a common element affecting all levels of stress measured by the adopted checklist, having the same psychological significance-the construct of stress. Three of these factors were named: the stages of alertness, resistance and exhaustion, which would correspond to the stages suggested by Selye (1950)-alarm, resistance and exhaustion - with the other situated between the phases of resistance and exhaustion. This newly identified phase came to be known as the "near-exhaustion phase", lending support to the four-phase stress model (Lipp, 2000).

\subsection{The Classification of Stress Symptoms into Phases}

The idea that the stress process consists of four phases instead of the three proposed by Selye (1950), was again evaluated in a recent study, in which a database comprising 37,454 participants was used. The participants' mean age was 37.1 years ( $\mathrm{SD}=11.6$ years), $61.1 \%$ of them being of the male sex. As for schooling, $40.1 \%$ reported having college education, $23.2 \%$ high school education and $17.5 \%$ were still in college. 
For the analysis, an item map based on the Rasch model (one parameter) was used, grounded on Item Response Theory (IRT), as suggested by Linacre (2014), in which items may be grouped according to the level of seriousness and the distance between them, considering the gaps created by these distances. Specifically, the application of this model sought to verify the structure of the groupings on the checklist according to individuals' levels within the latent construct (theta) and their symptoms (level of seriousness). The existence of four groupings of symptoms was again verified, confirming the existence of the four-phase stress model (Alarm, Resistance, Near-exhaustion and Exhaustion). Appendix shows the symptoms of stress in 37,454 subjects grouped according to the four phases.

\subsection{The Near-Exhaustion Phase}

The Near-exhaustion phase represents the moment at which the organism can no longer fully resist disequilibrium caused by the stress reaction and is on the verge of breaking down. The energy required to maintain homeostasis is not fully sufficient, and the individual oscillates between moments in which he/she is able to maintain equilibrium and those in which the organism's functions are impaired, with some functions accelerating (those controlled by the sympathetic nervous system-SNS) and others decelerating (those which depend on the parasympathetic nervous system-PSNS). To deal with situations that threaten homeostasis, the organism has the ability to initiate quick molecular and behavioral responses, by way of neuronal changes that allow for the reestablishment of internal equilibrium (homeostasis).

This fourth phase involves a dividing up of the Resistance phase, which Selye proposed would precede the moment the organism breaks down and subsequent entry into the Exhaustion phase. When one is situated in the Resistance phase and, by definition, is trying to resist life's pressures, this resistance would not extend to sudden entry into the final phase, Exhaustion. What was proposed by Lipp $(2000,2017)$ is that the Resistance phase would be characterized by the individual's success in adapting to the stressor, even with sterling efforts to achieve homeostasis. The permanence of the stressor or the appearance of other challenges would cause the individual's tolerance to decrease (he/she would no longer be able to fully resist all the strain) and signs of illness would begin to develop. The period of time between when one could adapt to the stressor (Resistance) and the final stage of total depletion of resistance (Exhaustion), marked by the onset of signs of illness, is what was designated as Near-exhaustion. Accordingly, Near-exhaustion is an intermediate phase in which the shock organ, i.e. the individual's area of greatest vulnerability, starts to manifest itself. Even when the stressor is eliminated, or the individual undergoes treatment, or even shakes off the condition of stress, the shock organ will already be defined. Therefore, the near-exhaustion phase is clinically important and its diagnosis allows preventive measures to be taken. 


\section{Conclusion}

The proposal that the four-phase model may better explain how the stress process develops, has received the support of research and should be considered as an alternative to the three-phase model proposed by Selye (1950). The list of symptoms, classified into four phases according to severity, might prove to be a useful method to help diagnose stress from its earliest to the most advanced stage, enabling not only individuals but also public and private organizations to conduct preventive measures that could reduce stress, and perhaps mental illness, in the workplace.

\section{Fund}

This study was supported by the Instituto de Psicologia e Controle do StressIPCS.

\section{Conflicts of Interest}

The authors declare no conflicts of interest regarding the publication of this paper.

\section{References}

American Psychiatric Association (APA) (2013). Diagnostic and Statistical Manual of Mental Disorders (5th ed.). Arlington, VA: American Psychiatric Association. https://doi.org/10.1176/appi.books.9780890425596

Everly Jr., G., \& Lating, J. M. (2013) The Clinical Guide to the Stress Response (3 ed.). New York: Springer. https://doi.org/10.1007/978-1-4614-5538-7_1

Fink, G. (2016). Outlined: Lessons from Anxiety. In F. George (Ed.), Stress: Concepts, Cognition, Emotion and Behavior (pp. 3-9). New York: Elsevier. https://doi.org/10.1016/B978-0-12-800951-2.00001-7

Holmes, T. H., \& Rahe, R. H. (1967). The Social Readjustment Rating Scale. Journal of Psychosomatic Research, 11, 213-218. https://doi.org/10.1016/0022-3999(67)90010-4

Lazarus, R. S., \& Folkman, S. (1984). Stress, Appraisal, and Coping. New York: Springer.

Linacre, J. M. (2014). Winsteps Rash Measurement Computer Program. Beaverton, OR: Winsteps. http://www.winsteps.com/index.htm

Lipp, M. E. N. (2000). Inventário de Sintomas para Adultos de Lipp. São Paulo: Casa do Psicólogo.

Lipp, M. E. N. (2017). O treino de controle do stress em grupo. Em C. B. Neufeld, \& B. Range (Eds.), Terapia Cognitivo Comportamental em Grupos (pp. 301-318). Porto Alegre: ArtMed.

Luijcks, R., Hermens, H. J., Bodar, L., Vossen, C. J., van Os, J., \& Richel Lousberg, R. (2014). Experimentally Induced Stress Validated by EMG Activity. PLoS ONE, 9, e95215. https://doi.org/10.1371/journal.pone.0095215

McCarty, R. (2016). The Alarm Phase and the General Adaptation Syndrome: Two Aspects of Selye's Inconsistent Legacy. In G. Fink (Ed.), Stress: Concepts, Cognition, Emotion and Behavior. Handbook of Stress (Vol. 1, pp. 13-19). Sydney: Elsevier. https://doi.org/10.1016/B978-0-12-800951-2.00002-9

McClelland, D. C., Ross, G., \& Patel, V. (1985). The Effect of Academic Examination on 
Salivary Norepinephrine and Immunoglobin Levels. Journal of Human Stress, 11, 52-59. https://doi.org/10.1080/0097840X.1985.9936739

Pacak, K., \& Palkovits, M. (2001). Stressor Specificity of Central Neuroendocrine Responses: Implications for Stress-Related Disorders. Endocrine Reviews, 22, 502-548. https://doi.org/10.1210/edrv.22.4.0436

Pacak, K., Palkovits, M., Yadid, G., Kvetnansky, R., Kopin, I. J., \& Goldstein, D. S. (1998). Heterogeneous Neurochemical Responses to Different Stressors: A Test of Selye's Doctrine of Nonspecificity. American Journal of Physiology, 275, 1247-1255. https://doi.org/10.1152/ajpregu.1998.275.4.R1247

Previdência Social (2011). Boletim Estatístico da Previdência Social. Benefícios Emitidos, segundo as espécies, 16.

Selye H. (1936). A Syndrome Produced by Diverse Nocuous Agents. Nature, 138, 32-39. https://doi.org/10.1038/138032a0

Selye, H. (1950). Stress and the General Adaptation Syndrome. British Medical Journal, 1, 1383-1392. https://doi.org/10.1136/bmj.1.4667.1383

Selye, H. (1965). Stress: A tensão da vida. São Paulo: Ibrasa.

Selye, H. (1975). Stress without Distress. New York: New American Library.

Selye, H. (1984). Stress: A tensão da vida. São Paulo: Ibrasa. Ediçao Revista.

Sherwood, A., Hill, L. K., Blumenthal, J. A., Adams Jr., K. F. Paine, N. J., Koch, G. G., O’Connor, C. M., Johnson, K. S., \& Hinderliter, A. L. (2017). Blood Pressure Reactivity to Psychological Stress Is Associated with Clinical Outcomes in Patients with Heart Failure. American Heart Journal, 191, 82-90. https://doi.org/10.1016/j.ahj.2017.07.003

Wethington, E. (2016). Life Events Scale. In G. Fink (Ed.), Stress: Concepts, Cognition, Emotion and Behavior. Handbook of Stress (Vol. 1, pp. 101-108). Sydney: Elsevier. https://doi.org/10.1016/B978-0-12-800951-2.00012-1

WHO (World Health Organization) (2011). Impact of Economic Crises on Mental Health. Copenhagen: WHO Regional Office for Europe.

Zangróniz, R., Martínez-Rodrigo, A., Pastor, J. M., López, M. T., \& Fernández-Caballero, A. (2017). Electrodermal Activity Sensor for Classification of Calm/Distress Condition. Sensors (Basel), 17, 2324. https://doi.org/10.3390/s17102324

Zuckerman, M. (1960). The Development of an Affect Adjective Checklist for the Measurement of Anxiety. Journal of Consulting Psychology, 24, 457-462.

https://doi.org/10.1037/h0042713 


\section{Appendix}

\section{Chart 1. List of Symptoms of Stress Classified According to Phase}

Phase 1: Alert Phase

1) Physical Symptoms

Cold hands or feet

Dry mouth

Knot in the stomach

Increase in transpiration

Muscle tension

Tightening of the mandibles or teeth grinding

Temporary diarrhea

Sudden sleeping problem

Tachycardia

Hyperventilation

Sudden and temporary hypertension

Change in appetite

\section{2) Psychological Symptoms}

Sudden increase in motivation.

Sudden increase in enthusiasm

Sudden desire to start new projects

Phase 2: Resistance Phase

1) Physical Symptoms

Memory problems

Constant tiredness

Constant feeling of being worn-out

2) Psychological Symptoms

Excessive emotional sensitivity

Constantly thinking about what is worrying you

Excessive irritability

Phase 3: Near-Exhaustion

1) Physical Symptoms

Generalized sensation of being unwell

Numbness of the extremities (fingers or toes)

Change in appetite

Appearance of dermatological problem

Episodes of High blood Pressure

Gastritis

Dizziness/sensation of floating

2) Psychological Symptoms

Doubt about yourself

Reduction in libido (interest in sex)

Phase 4: Exhaustion

1) Physical Symptoms 
Frequent bouts of diarrhea

Sexual problems

Sleeping problems

Nausea

Nervous ticks

Continued hypertension

Continued dermatological problems

Extreme changes in appetite

Excessive flatulence

Frequent bouts of dizziness

Ulcer

Heart problems

\section{2) Psychological Symptoms}

Inability to work

Nightmares

A sense of incompetence in all areas

Desire to run away from everything

Apathy, depression or prolonged anger

Excessive tiredness

Thinking and talking continuously about the same thing

High irritability with no apparent reason

Daily and continuous feelings of anxiety

Constant emotional sensitivity

Loss of sense of humor 